\title{
REGENERAÇÃO NATURAL DE TRÊS HECTARES DE FLORESTA OMBRÓFILA DENSA DE TERRA FIRME NA REGIÃO DO RIO URUCU-AM, BRASIL.'
}

\author{
Diógenes de Andrade LIMA FILHO ${ }^{2}$, Juan REVILLA ${ }^{2}$, Luiz de Souza COÊLHO ${ }^{2}$, \\ José Ferreira RAMOS ${ }^{2}$, José Lima dos SANTOS ${ }^{2}$, José Guedes de OLIVEIRA ${ }^{2}$
}

\begin{abstract}
Resumo - Neste trabalho estudou-se a regeneração natural de três hectares, em floresta ombrófila de terra - firme na regiāo do rio Urucu no município de Coari - $\mathrm{Am}$ ( $4^{0} 51^{\prime} 18^{\prime \prime}$ e $4^{0} 52^{\prime}$ ' 16" S; $65^{\circ} 17^{\prime} 58^{\prime \prime}$ e $65^{\circ} 20^{\prime} 01^{\prime \prime} \mathrm{W}$ ), abordando todos os indivíduos com altura total maior ou igual a $10 \mathrm{~cm}$ até $3,0 \mathrm{~m}$ e diâmetro à altura do peito (DAP) menor que $10 \mathrm{~cm}$. As espécies que mais se destacaram foram o Protium subserratum Engl. com valores médios de 30,55\%, Inga receptabilis (Vah1.) Wild.com 15,85\%, Oenocarpus bacaba com 12,35\% e Oenocarpus bataua com 11,42\%, entre as espécies arbóreas.
\end{abstract}

Palavras-chaves: Amazônia, Composiçāo florística, Inventário florístico, Regeneraçāo natural.

Natural Regeneration of Tree Hectares of "Terra Firme" Forest in the Petroleum Drilling Region of the Urucu River in the Amazon State, Brazil.

Abstract - Natural regeneration was studied of three hectares of "terra firme" in Coari Amazonas State, Brazil ( $4^{0} 51^{\prime} 18^{\prime \prime}$ e $4^{0} 52^{\prime} 16^{\prime \prime} \mathrm{S}$; $65^{\circ} 17^{\prime} 58^{\prime \prime}$ e $65^{\circ} 20^{\prime} 01^{\prime \prime W}$ ) forest all individuals of height $0,1-3,0 \mathrm{~m}$ and DBH less than $10 \mathrm{~cm}$.In the natural regeneration Protium subserratum Engl. stood out, with average values of $30,55 \%$ and Inga receptabilis (Vahl.) Wild. with 15,85\%, Oenocarpus bacaba with $12,35 \%$ and Oenocarpus bataua with $11,42 \%$, this among the arborescent species.

Key-words: Amazônia, Floristic composicion, Floristic inventory, natural regeneration.

\section{Introdução}

Com o avanço do progresso e da tecnologia de ponta, a humanidade vive a procura de alternativas para o uso e consumo dos recursos naturais em proporção mais racional possível. Assim, a Amazônia brasileira apresenta perspectivas de estudos básicos e aplicados para o conhecimento da vegetação da região, com objetivo do manejo para dar suporte no desenvolvimento silvicultural das espécies com finalidade de enriquecimento florístico e/ou florestal, seja para valor comercial ou perpetuação da floresta para a preservação e/ou conservação dos seus recursos naturais renováveis.

Segundo HOSOKAWA (1984), a análise da regeneração natural é de suma importância, pois a futura floresta vai depender do manejo dessa regeneração. Podendo-se obter florestas mais ricas (econômicas), e o grau de estabilidade ecológica permanecendo inalterado.

Após várias definições do estudo da regeneração natural, podemos citar pelo menos 2 conceitos: o estático e o dinâmico. O estático é aquele relacionado com a situação atual da

1Parte da Dissertação de Mestrado de Diógenes de Andrade Lima Filho, financiamento INPA/ PETROBRÁS.

${ }^{2}$ Instituto Nacional de Pesquisas da Amazônia, INPA/CPBO. Av. André Araújo, 2936, Petrópolis, CEP. 69083-000, Manaus, AM. Brasil, e-mail: diogenes@inpa.gov.br , site www.inpa.gov.br 
regeneração, como o número de indivíduos de cada fase juvenil. $O$ dinâmico refere aos processos silviculturais, que permitam o favorecimento da regeneração já existente e a indução em espécies, com regeneração ausente ou incipiente representadas no povoamento.

Neste trabalho, mostraremos as espécies que apresentaram o maior valor da regeneração natural, possibilitando assim, o conhecimento do sub-bosque na área de exploração de petróleo no Rio Urucu, que poderá ser necessário no estudo básico e aplicado de um manejo florestal nesta região, que servirá de ponto de partida para determinar a estrutura da floresta e sua caracterização florística.

\section{Material e Métodos}

Este trabalho foi realizado no Município de Coarí, Estado do Amazonas na margem direita do rio Solimões, na bacia do Rio Urucu, nas coordenadas situadas nos paralelos $4^{0}$ $51^{\prime} 18$ " e $4^{0} 52^{\prime} 16^{\prime}$ 'S e os meridianos $65^{\circ} 17^{\prime} 58^{\prime \prime}$ e $65^{\circ} 20^{\prime} 01^{\prime \prime} \mathrm{W}$, (Fig. 1). $O$ solo é classificado como cambissolo álico, de textura média, argiloso e de consistência dura, ocorrendo em relevo que varia de suave ondulado a ondulado (PETROBRAS, 1989).

O clima da região é classificado como "Afi", no esquema de Köppen, com uma flutuação anual, sendo a temperatura média mínima de $22,5^{\circ} \mathrm{C}$ e média máxima de $31,5^{\circ} \mathrm{C}$, RADAM (1978).

A regeneração natural dos 3 hectares estudados só foi possível em decorrência da instalação das unidades amostrais já existentes na área de estudo, onde indivíduos com diâmetro a altura do peito (DAP) maior ou igual a $10 \mathrm{~cm}$, já tinham sidos medidos e identificados. Assim, aproveitamos a forma e o tamanho das unidades de amostra desse nível e instalamos a metodologia da regeneração natural. Coletou-se e mediu-se todos os indivíduos com altura total maior ou igual a $10 \mathrm{~cm}$ até altura total maior ou igual a $3,0 \mathrm{~m}$ e DAP menor que $10 \mathrm{~cm}$, utilizou-se faixas de $2,0 \mathrm{~m}$ de largura por $2 \mathrm{~m}$ de comprimento em cada parcela de $10 \mathrm{~m}$ por $50 \mathrm{~m}$ do nível já existente. $\mathrm{O}$ sistema de amostragem adotado foi o sistemático que consistiu em 20 parcelas de $2 \mathrm{~m} \times 2 \mathrm{~m}$ para cada unidade de amostra estudado, (Fig. 2).

A coleta de dados foi realizada através da contagem do número de indivíduos de cada espécie dentro de cada classe de tamanho na unidade de amostra, identificando os mesmos de acordo com a taxonomia botânica. Vale ressaltar que as espécies do estrato herbáceo não foram incluídas na regeneração natural (arbórea), mas sim nas classes de tamanho das mesmas para determinar a sua diversidade florística.

A diversidade florística foi analisada através do quociente de mistura de Jentsch e da distribuição dos indivíduos por espécies, gêneros e famílias botânicas que ocorrem na área.

Lamprecht (1962), descreve que este quociente serve para indicar quantas árvores de cada espécie são encontradas em média no povoamento, 


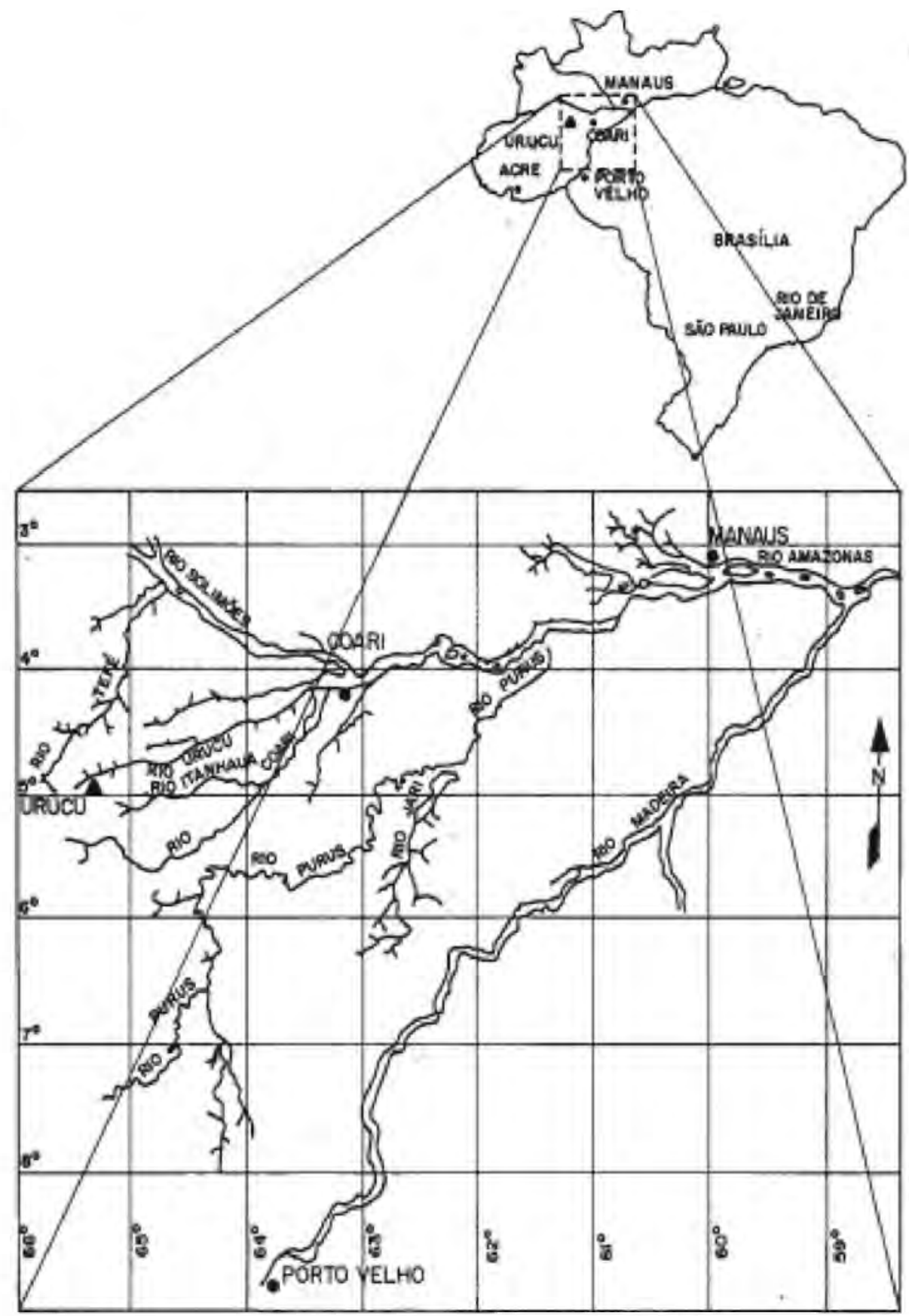

Figura 1. Localização da área de estudo, no Rio Urucu - AM. 


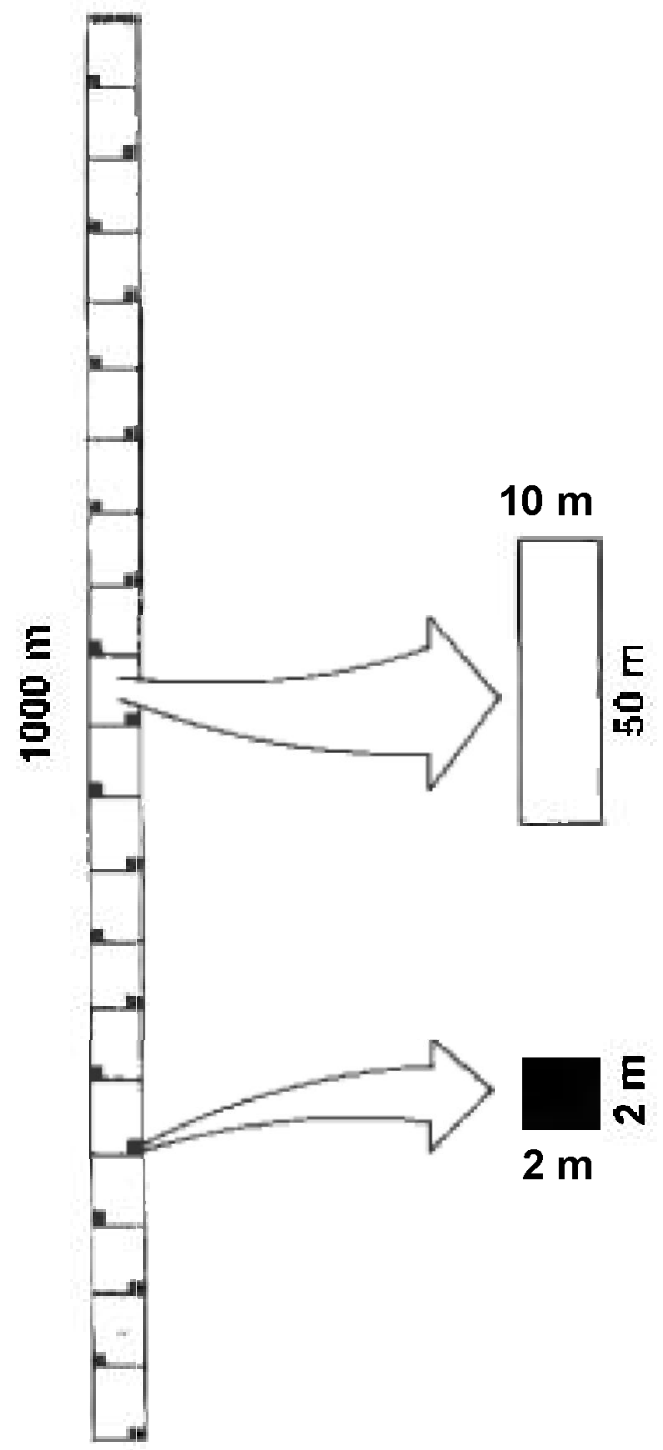

\section{LEGENDA:}

Nível I de Abordagem

Nível II de Abordagem

Figura 2. Forma e tamanho das unidades de amostras. 
dando assim, uma visão sobre a mistura das árvores em relação a área com as espécies. Onde, $\mathrm{QM}=\mathrm{N}^{\circ} \mathrm{de}$ espécies $/ \mathrm{n}^{\circ}$ de indivíduos.

Segundo Hosokawa (1981), o quociente de mistura de Jentsch dá uma idéia geral da diversidade florística da área em estudo. E foi utilizado por Finol (1971 e 1975), Jardim (1985) e Conceição (1990).

Neste trabalho considerou-se regeneração natural, os indivíduos com DAP $<10 \mathrm{~cm}$, referentes a freqüência, abundância e categoria de tamanho relativas. Onde, temos: $\mathrm{RN}=$ Abundância relativa + Freqüência relativa + Categoria de tamanho relativa.

Para obtenção da categoria de tamanho absoluta da regeneração natural (C.T. abs. RN.), baseou-se no critério sugerido por Finol (1971), aplicado por Longhi (1980) e modificado por Carvalho (1980; 1982), que adotou 6 classes de tamanho, as quais foram modificadas por Jardim (1985), com ampliação do limite superior do DAP para $20 \mathrm{~cm}$.

Neste estudo, foram consideradas 4 classes, assim determinadas:

Classe I= indivíduos com altura maior ou igual a $10 \mathrm{~cm}$ e menor que $50 \mathrm{~cm}$;

Classe II= indivíduos com altura maior ou igual a $50 \mathrm{~cm}$ e menor que $1,5 \mathrm{~m}$;

Classe III = indivíduos com altura maior ou igual a $1,5 \mathrm{~m}$ e menor que $3,0 \mathrm{~m}$;

Classe IV $=$ indivíduos com altura maior ou igual $3,0 \mathrm{~m}$ e DAP menor que $10 \mathrm{~cm}$.
Após o agrupamento dos indivíduos acima, calculou-se o peso de cada classe, ou seja, dividiu-se o número total de indivíduos de cada espécie pelo total de indivíduos em cada classe, obtendo assim, o peso dessa classe e utilizando a formula a seguir:

C.T.abs.RN. $=[(\mathrm{nI} . \mathrm{NI})+(\mathrm{nII} . \mathrm{NII})$ + (nIII.NIII) + (nIV.NIV)] $/ \mathrm{N}$

Onde:

nI, nII, nIII e nIV = número total de indivíduos de cada espécie nas respectivas classes de tamanho.

NI, NII, NIII e NIV = Peso de cada classe

$\mathrm{N}$ = número total de indivíduos da regeneração natural

A categoria de tamanho relativa da regeneração natural é a percentagem que corresponde a categoria de tamanho absoluta da regeneração natural de cada espécie em relação ao somatório da categoria de tamanho, ou seja, C.T. rel. RN. $=$ (C.T.abs.RN./ $\Sigma$ C.T.abs. dos RN.) x 100.

\section{Resultados e Discussão}

Foram registrados e identificados 6.430 indivíduos em 64 famílias, 154 gêneros e 207 espécies, distribuídos de acordo com a categoria de tamanho da regeneração natural em cada hectare estudado, (Tab. 1). Mas, esse número abrange a regeneração natural tanto arbórea como as espécies herbáceas. E portanto, as famílias que mais se destacaram em número de indivíduos foram Selaginellaceae com 3.935, Arecaceae com 260, Burseraceae com 221, Poaceae com 206, Mimosaceae 
e Melastomataceae com 138, e Lecythidaceae com 135. Todas essas 7 familias juntas representam $78,27 \%$ de todos os indivíduos estudados na área. Já as famílias que menos se destacaram foram Gnetaceae, Lacistemaceae, Olacaceae, Passifloraceae, Polygonaceae, Strelitziaceae e Tiliaceae, com apenas um indivíduo cada família, representando juntas $0,09 \%$ do total da abundância absoluta. Entretanto, as famílias que mais se destacaram em número de gêneros foram Annonaceae e Arecaceae com 8, Melastomataceae, Moraceae e Sapotaceae com 7, além de Fabaceae com 6 , representando $28,10 \%$ de todos os gêneros identificados. Enquanto isso, $45,31 \%$ das famílias estudadas apresentaram somente 1 gênero. Mas, em relação ao número de espécies, as famílias que mais se destacaram foram Arecaceae com 12 espécies, Melastomataceae com 11. Annonaceae e Sapotaceae com 10, Caesalpiniaceae e Moraceae com 9 espécies, correspondendo a $29,61 \%$ do total das espécies. Entretanto, 34,37\% das famílias estudadas apresentaram somente uma espécie cada uma.

Analisando a composição florística da regeneração natural, tanto para espécies arbóreas como para estrato herbáceo em comparação as espécies existentes com DAP maior ou igual a $10 \mathrm{~cm}$ (povoamento adulto), verificou-se que 19 famílias são exclusivamente deste nível, correspondendo a $22.78 \%$ do total de famílias encontradas na área de estudo. Enquanto 16 famílias são exclusivas das espécies com DAP maior ou igual a $10 \mathrm{~cm}$, representando $18,98 \%$ do total global das famílias identificadas, segundo Lima Filho (1996) (Tab. 2).

Deste modo, observou-se que as famílias Selaginellaceae, Cyclanthaceae, Adianthaceae, Cyateaceae, Drypteridaceae, Hymenophyllaceae, Maranthaceae, Piperaceae e Poaceae são famílias exclusivas do estrato herbáceo, pois são vegetação característica de subbosque e portanto, tem papel importante quanto a composição florística da área, exercendo como uma das principais funções a de cobertura do solo, para evitar os impactos causados pelos agentes intempéricos, além da contribuição ecológica nas mais variadas interações biológicas com os vegetais arbóreos.

Lima Filho (1996), observou que

Tabela 1. Distribuiçào da composiçấo florística da regeneraçâo natural de 3 hectares de floresta ombrófila densa de terra firme, na regiào do rio Urucu - AM.

\begin{tabular}{ccccc}
\hline Hectare & Individuos & Familias & Gèneros & Espécies \\
\hline 1 & 2.128 & 49 & 91 & 118 \\
2 & 2.511 & 49 & 93 & 113 \\
3 & 1.791 & 50 & 89 & 109 \\
Total & 6.430 & 64 & 154 & 207 \\
\hline
\end{tabular}


Tabela 2. Ocorrência das familias exclusivas na regeneraçào natural (sub-bosque) e povoamento adulto (DAP $\geq 10 \mathrm{~cm})$.

\begin{tabular}{|c|c|c|}
\hline Familias & Regeneraçăo Natural & $\begin{array}{l}\text { Povoamento Adulto } \\
\text { (DAP }>10 \mathrm{~cm})\end{array}$ \\
\hline Adianthaceae & $x$ & \\
\hline Anacardiaceae & & $\mathrm{x}$ \\
\hline Araceae & $x$ & \\
\hline Araliaceae & & $x$ \\
\hline Bixaceae & & $x$ \\
\hline Borraginaceae & & $x$ \\
\hline Caryocaraceae & & $x$ \\
\hline Celastraceae & & $x$ \\
\hline Connaraceae & $x$ & \\
\hline Convolvulaceae & $x$ & \\
\hline Cyateaceae & $x$ & \\
\hline Cyclanthaceae & $x$ & \\
\hline Cyperaceae & $x$ & \\
\hline Dryopteridaceae & $x$ & \\
\hline Heliconiaceae & $x$ & \\
\hline Hymenophyllaceae & $x$ & \\
\hline Icacinaceae & & $x$ \\
\hline Liliaceae & $x$ & \\
\hline Linaceae & $x$ & \\
\hline Malpighiaceae & & $x$ \\
\hline Maranthaceae & $x$ & \\
\hline Melismaceae & & $x$ \\
\hline Ochnaceae & & $x$ \\
\hline Passifloraceae & $x$ & \\
\hline Piperaceae & $x$ & \\
\hline Poaceae & $x$ & \\
\hline Quiinaceae & & $x$ \\
\hline Rhamnaceae & $x$ & \\
\hline Rhizophoraceae & & $x$ \\
\hline Rosaceae & & $x$ \\
\hline Selaginellaceae & $x$ & \\
\hline Theophrastaceae & $x$ & \\
\hline Verbenaceae & & $x$ \\
\hline \multirow[t]{2}{*}{ Vochysiaceae } & & $x$ \\
\hline & 19 & 15 \\
\hline
\end{tabular}


as demais famílias com as suas respectivas espécies são exclusivas nos 2 níveis de abordagem (regeneração natural e povoamento adulto), em geral está ligada também, a própria competição natural entre os mecanismos de sobrevivência, desenvolvidos por cada espécie, além da dispersão de sementes, tipo de solo e, principalmente, a ausência e presença de água dentro do solo. Estes fatores são determinantes para o empobrecimento ou enriquecimento de espécies em uma floresta tropical.

A Tabela 3 monstra a distribuição do número de indivíduos, gêneros e espécies por família botânicas, para a regeneração natural.

A composição florística da regeneração natural apresentou as famílias Arecaceae com 238 indivíduos, Burseraceae com 221, Mimosaceae com 138 e Melastomataceae com 121, obtendo no total 718 indivíduos, representando mais de $40 \%$ na área de estudo. Mas, quando se retrata o número de espécies, as famílias que mais se destacaram foram Annonaceae, Arecaceae, Melastomataceae e Sapotaceae com 10 respectivamente, representando $23,25 \%$ do total de espécies encontradas neste trabalho. Já em relação ao número de gêneros, as famílias que mais se destacaram foram Annonaceae com 8, Arecaceae, Caesalpiniaceae, Moraceae e Sapotaceae com 7 gêneros respectivamente, representando no total $28,21 \%$ do número de gêneros levantados neste estudo (Tab. 3).

No estrato herbáceo as famílias que obtiveram maior representatividade quanto ao número de indivíduos foram Selaginellaceae com 3.935 , seguidas das famílias Poaceae com 206, Hymenophyllaceae com 107, Maranthaceae com 103 e Ciperaceae com 100 indivíduos, obtendo no total juntas a soma de 4.451 indivíduos, representando $95,41 \%$ do total de abundância absoluta. Já em relação ao número de gêneros, há uma homogeneidade bem próxima entre eles, pois a família que mais se destacou foi a Poaceae com 3, que representa sozinha $12 \%$ de todos os gêneros encontrados, enquanto 12 famílias apresentaram somente 1 gênero cada, representando todas juntas em número de gênero $48 \%$. Observou-se que em número de espécies, o resultado também não foge a regra, pois as famílias mais representativas foram Piperaceae e Poaceae com 4 espécies cada uma representando $23,52 \%$.

Podemos concluir, que existe uma diferença na composição da regeneração natural para espécies arbóreas e estrato herbáceo, em relação do povoamento adulto estudado por Lima Filho (1996), principalmente quanto a homogeneidade de espécies e número de indivíduos por família. Essa diferença ocorre muitas vezes, até pelo caráter oportunista de algumas espécies, tais como a embaúba (Cecropia sp.) e o piquiá verdadeiro (Caryocar villosum), entre outras, que só alcançam o pleno desenvolvimento, quando ocorre a mortandade de outras espécies, abrindo clareiras naturais para que essas espécies possam chegar até o dossel. Isto pode ser evidenciado pelo 
Tabela 3. Distribuiçāo do número de individuos, gếneros e espếcies por família da regeneraçầo natural de 3 hectares de floresta densa ombrófila de terra firme.

\begin{tabular}{|c|c|c|c|c|}
\hline $\mathrm{N}^{\sigma}$ & Familias & Individuos & Gêneros & Espêcies \\
\hline 1 & Adianthaceae & 10 & 1 & 1 \\
\hline 2 & Annonaceae & 45 & 8 & 10 \\
\hline 3 & Apocynaceae & 3 & 2 & 2 \\
\hline 4 & Araceae & 5 & 2 & 3 \\
\hline 5 & Arecaceae & 260 & 8 & 12 \\
\hline 6 & Bignoniaceae & 23 & 3 & 4 \\
\hline 7 & Bombacaceae & 10 & 1 & 1 \\
\hline 8 & Burseraceae & 221 & 3 & 5 \\
\hline 9 & Caesalpiniaceae & 94 & 6 & 8 \\
\hline 10 & Cecropiaceae & 24 & 2 & 3 \\
\hline 11 & Chrysobalanaceae & 79 & 4 & 7 \\
\hline 12 & Clusiaceae & 27 & 3 & 4 \\
\hline 13 & Combretaceae & 2 & 2 & 2 \\
\hline 14 & Connaraceae & 78 & 2 & 2 \\
\hline 15 & Convolvulaceae & 2 & 1 & 1 \\
\hline 16 & Cyateaceae & 22 & 2 & 2 \\
\hline 17 & Cyclanthaceae & 4 & 1 & 2 \\
\hline 18 & Cyperaceae & 100 & 2 & 2 \\
\hline 19 & Dichapetalaceae & 3 & 2 & 2 \\
\hline 20 & Dilleniaceae & 42 & 1 & 1 \\
\hline 21 & Dryopteridaceae & 3 & 2 & 2 \\
\hline 22 & Elaeocarpaceae & 7 & 1 & 1 \\
\hline 23 & Euphorbiaceae & 14 & 6 & 7 \\
\hline 24 & Fabaceae & 10 & 7 & 7 \\
\hline 25 & Flacourtiaceae & 7 & 1 & 2 \\
\hline 26 & Gnetaceae & 1 & 1 & 1 \\
\hline 27 & Heliconiaceae & 22 & 1 & 2 \\
\hline 28 & Hippocrateaceae & 35 & 2 & 3 \\
\hline 29 & Humiriaceae & 5 & 2 & 3 \\
\hline
\end{tabular}


Tahela 3. Continuacào

\begin{tabular}{|c|c|c|c|c|}
\hline $\mathrm{N}^{0}$ & Familias & Individuos & Gêneros & Espécies \\
\hline 30 & Hymenophyllaceae & 107 & 1 & 1 \\
\hline 31 & Lauraceae & 23 & 4 & 5 \\
\hline 32 & Lacistemaceae & 1 & 1 & 1 \\
\hline 33 & Lecythidaceae & 135 & 2 & 5 \\
\hline 34 & Liliaceae & 7 & 1 & 1 \\
\hline 35 & Linaceae & 2 & 1 & 1 \\
\hline 36 & Loganiaceae & 5 & 1 & 1 \\
\hline 37 & Maranthaceae & 103 & 2 & 3 \\
\hline 38 & Melastomataceae & 138 & 7 & 11 \\
\hline 39 & Meliaceae & 3 & 1 & 2 \\
\hline 40 & Menispermaceae & 23 & 2 & 3 \\
\hline 41 & Mimosaceae & 138 & 4 & 4 \\
\hline 42 & Monimiaceae & 13 & 1 & 4 \\
\hline 43 & Moraceae & 35 & 7 & 9 \\
\hline 44 & Myristicaceae & 99 & 2 & 2 \\
\hline 45 & Myrsinaceae & 8 & 1 & 2 \\
\hline 46 & Myrtaceae & 8 & 2 & 2 \\
\hline 47 & Nyctaginaceae & 7 & 1 & 1 \\
\hline 48 & Olacaceae & 1 & 1 & 1 \\
\hline 49 & Passifloraceae & 1 & 1 & 1 \\
\hline 50 & Piperaceae & 83 & 1 & 4 \\
\hline 51 & Poaceae & 206 & 3 & 4 \\
\hline 52 & Polygalaceae & 3 & 1 & 1 \\
\hline 53 & Polygonaceae & 1 & 1 & 1 \\
\hline 54 & Rhamnaceae & 16 & 1 & 1 \\
\hline 55 & Rubiaceae & 51 & 5 & 6 \\
\hline 56 & Sapindaceae & 6 & 3 & 4 \\
\hline 57 & Sapotaceae & 71 & 7 & 10 \\
\hline 58 & Selaginellaceae & 3.935 & 1 & 1 \\
\hline 59 & Simaroubaceae & 5 & 2 & 4 \\
\hline 60 & Sterculiaceae & 6 & 1 & 1 \\
\hline 61 & Strelitziaceae & 1 & 1 & 1 \\
\hline 62 & Theophastaceae & 2 & 1 & 1 \\
\hline 63 & Tiliaceae & 1 & 1 & 1 \\
\hline \multirow[t]{2}{*}{64} & Violaceae & 28 & 3 & 5 \\
\hline & & 6.430 & 154 & 207 \\
\hline
\end{tabular}


valor do número de indivíduos da regeneraçã̃o natural e do estrato herbáceo dessas espécies, (Tab. 3).

$\mathrm{O}$ quociente de mistura de Jentsch está ilustrado na Tabela 4, e foi cálculo para os 3 hectares estudados na regeneração natural.

Segundo o trabalho realizado por Lima Filho (1996), a floresta estudada apresentou em média um quociente de mistura de Jentsch de 1:7, mas quando se estratifica a floresta em niveis de abordagem, é observado que para o povoamento adulto, o quociente de mistura de Jentsch é de $1: 3$. Entretanto, quando analisamos a regeneração natural , temos um QM de $1: 19$, sendo a amostra do ha 3 a mais heterogênea com QM 1:16, enquanto a do ha 2 é a mais homogênea com $1: 22$, já a amostra do ha 1 ficou bem próximo da média deste nível de abordagem, com QM de 1:18.

Fica evidenciado na Tabela 4, que a maior heterogeneidade da floresta está no povoamento adulto em relação a regeneração natural , porém a explicação se dá pelo número de indivíduos em competição por um espaço maior, além é claro, pelo próprio mecanismo de sobrevivência da seleção natural.

$\mathrm{Na}$ Tabela 5 , encontra-se as 10 espécies que apresentaram os maiores valores do parâmetro regeneração natural nos 3 hectares pesquisados. No hectare 1(aeroporto), encontrou-se 138,92 que representa mais de $46 \%$ de todos os indivíduos estudados. Observou-se que as espécies com maiores valores desse parãmetro foram Protium subserratum com $(46,39)$ representando $15,46 \%$. Oenocarpus bacaba com $(12,28)$ representando $4,09 \%$ e Connarus sp. com $(12,12)$ representando $4,04 \%$. Enquanto 33 espécies obteram indices de percentagens inferiores a $1 \%$, representando todas juntas mais de $34 \%$ das espécies encontradas nesta área.

A freqüência relativa da regeneração natural, mostra que as espécies com maiores valores são Protium subserratum e Inga receptabilis com $5,63 \%$ cada uma, seguida do Connarus sp. com 4,13\%. Entretanto, 29 espécies mostram índices variando de $1,12 \%$ a $3,75 \%$ e 65 espécies apresentando valores inferiores a $1 \%$.

A abundância relativa da regeneração natural, mostra que as espécies mais abundantes são Protium subserratum com $18,28 \%$ e

Tabela 4. Quociente de mistura de Jentsch.

\begin{tabular}{cccc}
\hline hectare & Espécies & Individuos & QM \\
\hline 1 & 118 & 2.128 & $1: 18$ \\
2 & 113 & 2.514 & $1: 22$ \\
3 & 109 & 1.791 & $1: 16$ \\
média & 113,33 & $2.143,33$ & $1: 19$ \\
total & 340 & 6.430 & \\
\hline
\end{tabular}


Tabela 5. Relação das 10 espécies com maiores valores da regeneraçăo natural dos 3 hectares / Rio Urucu.

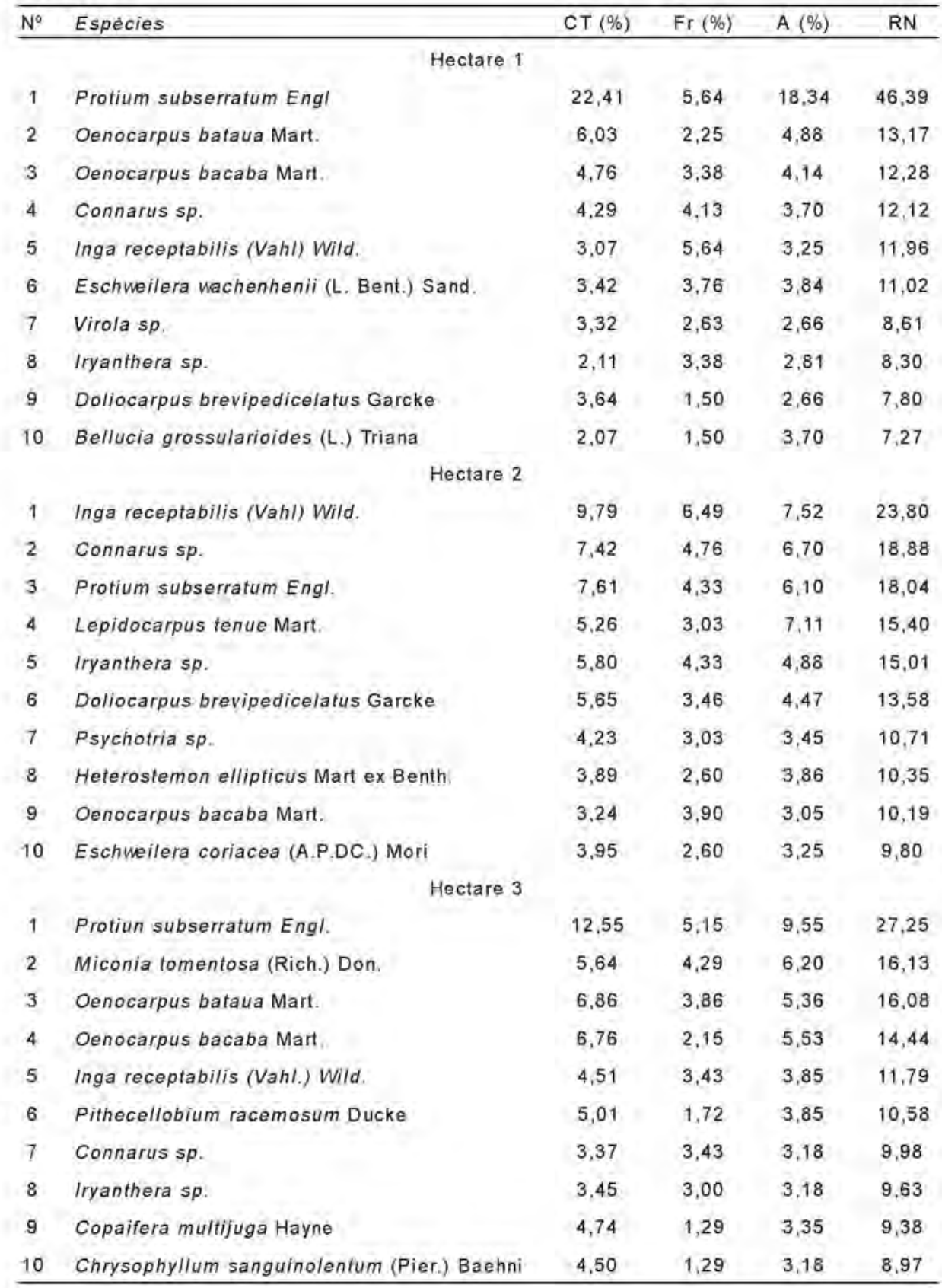

Legenda:

CT $(\%)$ : Categoria de Tamanho Relativa

Fr $(\%)$ : Freqüència Relativa

A $(\%)$ : Abundância Relativa

RN : Regeneração Natural 
Oenocarpus bataua com 4,88\% e Oenocarpus bacaba com 4,14\%. Mas, 22 espécies apresentam abundância relativa entre 1,03 a 3,84\% e 72 espécies apresentam valores inferiores a $1 \%$.

A categoria de tamanho da regeneração natural é caracterizada principalmente, pelas espécies que obteram os maiores percentuais, tais como Protium subserratum com $22,41 \%$ e Oenocarpus bataua com $6,03 \%$ e Oenocarpus bacaba com $4,76 \%$. Entretanto, 21 espécies apresentaram índices oscilando entre $1,06 \%$ a $4,29 \%$ e 73 espécies obteram indices inferiores a $1 \%$.

No hectare 2 ( RUC - 25), as 10 espécies que apresentaram os maiores valores desse parâmetro, obtiveram 145,76 que representam mais de $48 \%$ de todos os valores pesquisados nesta área. As espécies que alcançaram os melhores valores foram Inga receptabilis com $(23,80)$ representando $7,93 \%$ e Connarus sp. com $(18,88)$ representando 6,29\% e Protium subserratum com $(18,03)$ representando $6,01 \%$. Já 44 espécies, obteram índices de percentagens inferiores a $1 \%$, representando no total das espécies estudadas deste hectare mais de $45 \%$.

A freqüência relativa da regeneração, mostra que as espécies de maior ocorrência são Inga receptabilis com $6,49 \%$, Connarus sp. com $4,76 \%$, Protium subserratum e Iryanthera sp. com 4,32\% cada uma. Já 22 espécies apresentaram valores oscilando entre $1,29 \%$ a $3,46 \%$ e 70 espécies apresentaram valores inferiores a $1 \%$.

As espécies mais abundantes neste hectare da regeneração natural são Inga receptabilis com 7,52\%, Lepidocaryum tenue com $7,11 \%$, Connarus sp. com $6,70 \%$ e Protium subserratum com $6,09 \%$. Temos ainda, 21 espécies com valores de abundância entre $1,01 \%$ a $4,87 \%$ e 71 espécies apresentam valores inferiores a $1 \%$.

A categoria de tamanho da regeneração natural deste hectare é representada por Inga receptabilis com $9,78 \%$, Protium subserratum com $7,61 \%$ e Connarus sp. com 7,42\%. Entretanto, 19 espécies apresentaram índices entre $1,13 \%$ a $5,80 \%$ e 74 espécies com valores inferiores a $1 \%$.

No hectare 3 (estação de fluídos), as 10 espécies com maiores valores de regeneração natural, obteram $(134,23)$ representando mais de $44 \%$ dos valores totais deste parâmetro. As espécies com maiores valores foram Protium subserratum com $(27,25)$ representando mais de $9 \%$, Miconia tomentosa com $(16,13)$ representando $5,38 \%$ e Oenocarpus bataua com $(16,08)$ representando $5,36 \%$. De outro modo, 58 espécies apresentaram valores inferiores a $1 \%$ representando mais de $63 \%$ de todas as espécies encontradas neste hectare.

A freqüência relativa da regeneração natural nesta amostra, teve as seguintes espécies com maiores valores, as quais foram Protium sp. com $5,15 \%$, Miconia tomentosa com 4,29\%, Oenocarpus bataua com $3,86 \%$, Connarus sp. e Inga sp. com 3,43\% cada uma. Temos ainda, 21 espécies oscilando entre $1,28 \%$ a $3 \%$ e 65 espécies apresentaram valores inferiores a $1 \%$. 
As espécies mais abundantes neste parâmetro foram Protium subserratum com 9,54\%, Miconia tomentosa com $6,19 \%$, Oenocarpus bataua com $5,36 \%$. Já 23 espécies apresentaram índices entre $1 \%$ a $3,85 \%$ e 64 espécies alcançaram valores inferiores a $1 \%$.

Em relação a categoria de tamanho, as espécies que obteram os maiores valores foram: Protium subserratum com $12,55 \%$, Oenocarpus bataua com $6,85 \%$, Oenocarpus bacaba com 6,75\%, Miconia tomentosa com 5,64\% e Pithecellobium racemosum com 5,01\%. Entretanto, encontrou-se 16 espécies com índices oscilando entre $1,15 \%$ a $4,74 \%$ e 70 espécies apresentaram valores inferiores a $1 \%$.

Conforme resultados apresentados acima, a espécie Protium subserratum, obteve o maior valor da regeneração natural na área estudada, com uma média de $10,18 \%$ de todas as demais espécies analisadas neste parâmetro. Mas, vale ressaltar que na área do hectare 1 (aeroporto), essa espécie alcançou mais de $15 \%$ da regeneração natural.

\section{Conclusão}

As famílias Selaginellaceae, Arecaceae, Burseraceae e Poaceae, foram as mais dominantes do subbosque, representando mais de $71 \%$ dos indivíduos pesquisados. Já em relação a regeneração natural, temos as famílias Arecaceae, Burseraceae, Mimosaceae e Melastomataceae como as mais abundantes, obtendo uma percentagem acima dos $40 \%$.

Analisando as 30 espécies que alcançaram os maiores valores da regeneração natural, conclui-se que apenas Eschweilera wachenhenii, Eschweilera coriacea, Eschweilera sp., Chrysophyllum sp., Pithecelobium racemosum e Copaifera multijuga, são espécies que alcançam o dossel, e portanto, representam em torno de $5 \%$ da regeneração natural pesquisada.

Concluímos que a diferença da composição florística entre os indivíduos com DAP maior ou igual a $10 \mathrm{~cm}$ e a regeneração natural, está relacionada com a sucessão natural à longo prazo. Assim, estas metodologias silviculturais atualmente em uso, nos mostraram uma contradição, pois esses métodos direcionam quase sempre a inclusão de indivíduos jovens (regeneração natural) das espécies que compõem o dossel para a manutenção das florestas, mas o que se obteve foi o contrário, onde apenas $5 \%$ dessas espécies poderão alcançar o dossel pelas suas próprias características botânicas.

\section{Bibliografia citada}

Carvalho, J.O.P. 1980. Inventário diagnóstico da regeneração natural da vegetação em área da Floresta Nacional do Tapajós, Belém, EMBRAPA/CPATU. Bol. Pesq. (2): 1-20. 20p.

Carvalho, J.O.P. 1982. Analise estrutural da regeneração natural em floresta tropical densa na região do Tapajós no Estado do Pará. Tese de Mestrado. Curutiba. UFPR. 63p

Conceição, M.C.A. 1990. Análise estrutural de uma floresta de várzea no estado do Pará. Tese de Mestrado. Curitiba. UFPR. 170 p.

Finol, U.H. 1971. Nuevos parametros a consideraiser en el analisis estructural de las selvas virgene tropicales. Rev. For. Venez. 14 (21) : 29-42. 
Finol, U.H. 1975. La silvicultura em la Orinoquia venezoelana. Rev. For. Venez. 18 (25):37-144.

Hosokawa, R.T. 1981. Manejo de florestas tropicais úmidas em regime de rendimento sustentado. UFPR. Curitiba. Relatório. $125 \mathrm{p}$.

Hosokawa, R.T. 1984. Introdução ao manejo de florestas naturais em regime de rendimento sustentado. UFPR. 27p.

Jardim, F.C. 1985. Estrutura de floresta equatorial úmida da estação experimental de silvicultura tropical do INPA. Tese de Mestrado. Manaus. INPA/UFA. 195 p.

Lamprecht, H. 1962. Ensayo sobre unos metodos para el analisis estructural de los bosques tropicales. Acta Cientifica Venezolana. 13 (2) : 57-65.

Lima Filho, D.A. 1996. Caracterização Florística de 3 hectares de floresta de terra firme do Rio Urucu - AM. Tese de Mestrado. Manaus. INPA/UA. 162 p.

Longhi, S.V. 1980. A estrutura de uma floresta natural de Araucária angustifolia (Bert. O. Ktze, sul do Brasil). Tese de mestrado. Curitiba. UFPR. 198 p.

Petrobras. 1989. Relatório Individual do Meio Ambiente - RIMA. Urucu. 74 - 77 p.

RADAM-BRASIL. 1978. Programa de Integração Nacional. Levantamentos de Recursos Naturais. Vol.18 (Manaus RADAM/Projeto - DBPM). Ministério das Minas e Energia. $626 \mathrm{p}$.

Aceito para publicação em 30/08/2002 
